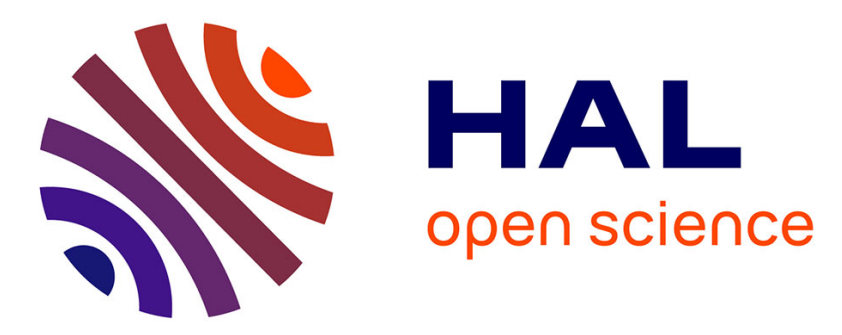

\title{
Induction of Phenotype Modifying Cytokines by FERMT1 Mutations
}

Anja Heinemann, Yinghong He, Elena Zimina, Melanie Boerries, Hauke Busch, Nadja Chmel, Thorsten Kurz, Leena Bruckner-Tuderman, Cristina Has

\section{- To cite this version:}

Anja Heinemann, Yinghong He, Elena Zimina, Melanie Boerries, Hauke Busch, et al.. Induction of Phenotype Modifying Cytokines by FERMT1 Mutations. Human Mutation, 2011, 32 (4), pp.397. 10.1002/humu.21449 . hal-00618181

\section{HAL Id: hal-00618181 \\ https://hal.science/hal-00618181}

Submitted on 1 Sep 2011

HAL is a multi-disciplinary open access archive for the deposit and dissemination of scientific research documents, whether they are published or not. The documents may come from teaching and research institutions in France or abroad, or from public or private research centers.
L'archive ouverte pluridisciplinaire HAL, est destinée au dépôt et à la diffusion de documents scientifiques de niveau recherche, publiés ou non, émanant des établissements d'enseignement et de recherche français ou étrangers, des laboratoires publics ou privés. 
Human Mutation

WILEY

\section{Induction of Phenotype Modifying Cytokines by FERMT1} Mutations

\begin{tabular}{|r|l|}
\hline Journal: & Human Mutation \\
\hline Manuscript ID: & humu-2010-0312.R1 \\
\hline Wiley - Manuscript type: & Research Article \\
\hline Date Submitted by the & $18-$ Nov-2010 \\
\hline Complete List of Authors: & $\begin{array}{l}\text { Heinemann, Anja; University of Freiburg, Dermatology } \\
\text { He, Yinghong; University of Freiburg, Dermatology } \\
\text { Zimina, Elena; University of Freiburg, Dermatology } \\
\text { Boerries, Melanie; Freiburg Institute for Advanced Studies } \\
\text { Busch, Hauke; Freiburg Institute for Advanced Studies } \\
\text { Chmel, Nadja; University of Freiburg, Dermatology } \\
\text { Kurz, Thorsten; University of Freiburg, Center for Systems Biology } \\
\text { Bruckner-Tuderman, Leena; University of Freiburg, Dermatology; } \\
\text { Freiburg Institute for Advanced Studies } \\
\text { Has, Cristina; University of Freiburg, Dermatology }\end{array}$ \\
\hline \hline Key Words: & $\begin{array}{l}\text { Kindler syndrome, epidermolysis bullosa, fibrosis, TGF , cytokine, } \\
\text { fermitin, kindlin }\end{array}$ \\
\hline \hline
\end{tabular}

\section{SCHOLARONE $^{\text {m }}$ Manuscripts}




\section{Induction of Phenotype Modifying Cytokines by FERMT1 Mutations}

Anja Heinemann ${ }^{1}$, Yinghong $\mathrm{He}^{1}$, Elena Zimina ${ }^{1}$, Melanie Boerries ${ }^{2,3}$, Hauke Busch $^{2,3}$, Nadja Chmel $^{1}$, Thorsten Kurz ${ }^{4}$, Leena Bruckner-Tuderman ${ }^{1,2}$, Cristina Has ${ }^{1}$

${ }^{1}$ Department of Dermatology, University of Freiburg, Freiburg, Germany; ${ }^{2}$ Freiburg Institute for Advanced Studies, School of Life Sciences -LIFENET, Freiburg, Germany; ${ }^{3}$ Center for Biosystems Analysis, Freiburg, Germany; ${ }^{4}$ Core Facility Genomics, Centre for Systems Biology, University Freiburg, Germany

Short title: Kindlin defects and fibrosis

\section{Author for correspondence:}

Dr. Leena Bruckner-Tuderman,

Department of Dermatology,

University Medical Center Freiburg,

Hauptstr. 7, 79104 Freiburg, Germany

Tel :+49-761-270-6716,

Fax :+49-761-270-6936,

E-Mail: bruckner-tuderman@uniklinik-freiburg.de 


\begin{abstract}
Kindler syndrome (KS) is a progressive skin disorder caused by FERMT1 mutations. Early in life, KS manifests as a mechanobullous disease reflecting diminished cell adhesion, but the mechanisms of its later phenotypic features, progressive poikiloderma and mucocutaneous fibrosis, remain elusive. The FERMT1 gene product and KS protein, kindlin-1, is an epithelial-specific phosphoprotein involved in integrin beta-1 activation, without an obvious link to dermal connective tissue. Here we show how lack of intracellular kindlin-1 in epidermal keratinocytes leads to profound changes in another skin compartment, the dermis. Kindlin-1 deficient keratinocytes respond to cell stress by upregulating the expression of cytokines such as IL-20, IL-24, TGF- $\beta 2$, IL1F5, PDGFB and CTGF. These launch - via paracrine communication - an inflammatory response in the dermis, accompanied by the presence of TGF- $\beta$, IL- 6 and CTGF, activation of fibroblasts and their differentiation to myofibroblasts, which secrete and deposit increased amounts of extracellular matrix proteins. These data are concordant with a model wherein repeated cycles of epidermal cell stress, cytokine secretion, dermal inflammation and profibrotic processes underlie mucocutaneous fibrosis in KS.
\end{abstract}

Key words: Kindler syndrome, kindlin, fermitin, epidermolysis bullosa, fibrosis, TGF$\beta$, cytokine 


\section{INTRODUCTION}

Kindlins are evolutionarily conserved FERM (Four-point-one, ezrin, radixin, moesin) domain-containing proteins, which have recently emerged as key regulators of integrin activation (Moser, et al., 2009). Among them, kindlin-1 is expressed in epithelial cells, predominantly in the skin, the intestine and the kidney, and loss-of-function mutations in its gene FERMT1 (KIND1; MIM\#607900) cause the Kindler syndrome (KS; MIM 173650). KS manifests with skin blistering in the childhood, but later photosensitivity and progressive generalized poikiloderma dominate the phenotype (Fine, et al., 2008; Lai-Cheong, et al., 2009). Interestingly, many patients develop symptoms like webbing of the fingers, pseudoainhum, ectropion, oesophageal or urethral stenosis (Has, et al., 2008a; Mansur, et al., 2007), which reflect mucocutaneous fibrosis. So far, $>40$ distinct FERMT1 mutations have been reported including large deletions, splice site, nonsense, and frameshift mutations, all of them leading to premature termination codons and, consequently, to complete lack of kindlin1 in epithelial cells (Lai-Cheong and McGrath, 2010).

Although all patients have null mutations, the severity of the symptoms spans a broad spectrum suggesting a contribution of secondary processes guided by modifying factors. In KS skin and in the kindlin-1 knockout mouse, disorganized basal keratinocytes lose their proper architecture, polarization and the boundary to the dermis and exhibit minimal proliferation (Herz, et al., 2006; Ussar, et al., 2008). These abnormalities correlate strongly with in vitro findings on kindlin-1 deficient keratinocytes (Has, et al., 2009; Herz, et al., 2006; Ussar, et al., 2008). However, since kindlin-1 is not expressed in fibroblasts, the mechanisms of the significant dermal part of the KS phenotype, i.e. the progressive soft tissue fibrosis in the skin and the oral, ophthalmic and urogenital mucosa remain unexplained.

The skin is a prime example of an organ where epithelial-mesenchymal communication pathways are essential for tissue development, homeostasis and regeneration. 
The epidermis, which is purely epithelial and avascular, and the mesenchymal dermis, which contains blood vessels, nerves and adnexal structures embedded in connective tissue, communicate via soluble mediators, such as cytokines and growth factors, to maintain physiological tissue functions (Werner, et al., 2007).

Against this background, we addressed the pathogenesis of dermal changes in KS by exploring cytokine profiles of KS keratinocytes, by characterizing KS skin fibroblasts in vitro, and by validating the findings in KS skin in vivo. We show that kindlin-1 negative keratinocytes upregulate the expression of interleukin (IL)-24, IL-20, transforming growth factor- $\beta 2$ (TGF- $\beta 2$ ), interleukin-1 family member 5 (IL1F5), platelet derived growth factor B (PDGFB) and connective tissue growth factor (CTGF), and that KS fibroblasts exhibit an activated phenotype. These findings correlate with the presence of macrophages and mediators of fibrosis, like $\alpha$-smooth muscle actin (SMA), TGF- $\beta 1$, IL- 6 and CTGF, in KS skin. Based on this we predict that mutations in the FERMT1 gene cause epithelial cell stress and, as a stress response, secretion of cytokines that mediate local inflammation and fibrosis. 


\section{MATERIAL AND METHODS \\ Patients and Mutation Detection}

Nine KS patients with known FERMT1 mutations were included in this study (Table 1). After informed consent, EDTA-blood and skin samples were obtained for diagnostic purposes. Mutation detection was described in detail elsewhere (Has, et al., 2008a). The GenBank reference sequence was NM_017671.4. Nucleotide numbering reflects cDNA numbering with +1 corresponding to the A of the ATG translation initiation codon in the reference sequence according to the HGVS guidelines. The study was approved by the ethics committee of the University of Freiburg and was conducted in accordance to the Helsinki protocols.

\section{Cell Culture and Cell Treatments}

Cell lines derived from normal human keratinocytes (NK) and KS patient 4 (KSK), as well as primary keratinocytes of KS patients 1 and 8, and of control individuals have been characterized previously (Has, et al., 2009; Has, et al., 2008a; Kern, et al., 2007). Keratinocytes were cultured in defined keratinocyte growth medium (KGM, Invitrogen, Karlsruhe, Germany). Cell lines were used for experiments in passages 5 to 18 , and primary cells in passages 2 to 4 . Primary dermal fibroblasts were isolated from biopsies of patients 1 , 2 and 3 and of three age-matched controls, and grown in Dulbecco's modified Eagle's medium (DMEM, Invitrogen) containing 10\% fetal calf serum (FCS) and 2mM glutamine, penicillin G, streptomycin and amphotericin B. They were used for experiments in passages 2 to 5.

For cytokine treatment, primary normal fibroblasts (NF) were seeded in 6 well plates, and allowed to adhere overnight. The next day the medium was replaced with DMEM with 
$1 \%$ FCS. Ten $\mathrm{ng} / \mathrm{ml}$ of recombinant human IL-20 and IL- 24 , with or without $5 \mu \mathrm{g} / \mathrm{ml}$ of blocking antibodies to rhIL20 and rhIL24 (both from R\&D Systems, Wiesbaden, Germany) were added. As a vehicle control the same amount of PBS was used. At different time points cells were harvested for RNA and protein analysis.

$\underline{\text { To evaluate potential paracrine mechanisms, NF were treated with keratinocyte- }}$ $\underline{\text { conditioned media, and the expression of extracellular matrix proteins, collagen I, tenascin } \mathrm{C}}$ and fibronectin, was assessed in NF media and lysates (Ghaffari, et al., 2009). To collect keratinocyte conditioned media, NK and KSK (in passages 10-15) were cultured in KGM without supplements for 24 hours. NF from two control individuals (passages 5) were treated with the above conditioned media for 24 and 48 hours in triplicate experiments. Media and lysates of NF were collected, and total protein was quantified as described below under "Protein Extraction and Immunoblotting". Normalized amounts of media and lysates were analyzed by immunoblotting.

\section{Induction of Cell Stress}

Cell stress was induced in vitro using three different experimental systems, cellular hypoxia, oxidative stress and ultraviolet (UV) irradiation. To mimic cellular hypoxia, confluent NK and $\mathrm{KSK}$ in $\mathrm{KGM}$ were treated with $1000 \mu \mathrm{M} \mathrm{CoCl}_{2}$ (Chen and Chang, 2009), or with vehicle for 1 hour. To induce oxidative stress, NK and KSK were incubated with $1000 \mu \mathrm{M} \mathrm{H}_{2} \mathrm{O}_{2}$ or vehicle for 4 hours. For evaluation of effects of UV-irradiation, NK and KSK were treated with 30 or $60 \mathrm{~mJ} / \mathrm{cm}^{2}$ of UVB (Waldmann GmbH, VS-Schwenningen, Germany). Controls were treated identically but not irradiated. For each condition, three experiments were performed. RTqPCR reactions were done in duplicate with three different $\underline{\text { RNAs. For ELISA, keratinocyte lysates and media were collected from three different }}$ cultures. 


\section{RNA Extraction, Reverse-Transcription PCR and Real-Time Quantitative PCR}

Total RNA was extracted with QIAmp RNA blood mini kit (Qiagen, Hilden, Germany) from subconfluent cells. Reverse transcription (RT) was performed with Advantage RT-for-PCR Kit from 500 ng total RNA (BD Biosciences, Heidelberg, Germany). To ensure equal loading in semiquantitative RT-PCR, glyceraldehyde-3-phosphate dehydrogenase $(G A P D H)$ was simultaneously amplified. The PCR products were assessed on 1.5\% agarose gels. Real-time quantitative PCR (RTqPCR) was carried out using the RealTime PCR Detection System (BioRad CFX96). The reactions were performed in $20 \mu 1$ volume containing $15 \mathrm{ng}$ of cDNA and ready to use iQ-SYBR Green Supermix (BioRad, München, Germany). The data were analyzed using the BioRad CFX Manager Software (version 1.5). The expression levels were calculated relative to those of hypoxanthine phosphoribosyltransferase (HPRT1) and of 18s RNA. Efficiencies were determined for each marker and shown to be close to the efficiency of the normalizing marker. Relative expression

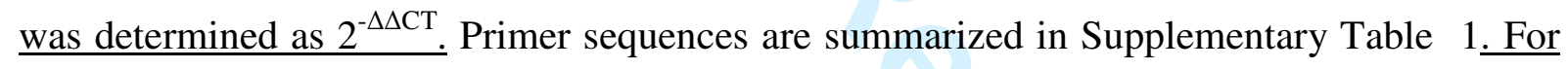
each experiment, three different RNAs were used and each reaction was performed in duplicate.

\section{Microarray Processing and Data Analysis}

RNA concentration was determined using a UV-Vis spectrophotometer NanoDrop® ND-1000 (NanoDrop Technologies, Wilmington, USA). RNA integrity and quality were estimated on Agilent 2100 Bioanalyzer (Agilent Technologies, Palo Alto, CA), and RNA integrity number index was calculated for each sample using the Agilent 2100 Expert software. This provides a numerical assessment of the integrity of RNA that facilitates the standardization of the quality interpretation; for microarray processing, only RNAs with 
integrity number $>8.0$ were further processed to reduce experimental biases due to poor RNA quality.

For the expression analyses we used the human gene expression microarrays from Agilent (Design ID 014850) based on the 4 x 44k design format. Sample labeling and hybridization were performed according to the Agilent One-Color Microarray-Based Gene Expression Analysis protocol. Briefly, for the hybridization of the microarrays, $0.5 \mu \mathrm{g}$ of total RNA was reverse transcribed into cDNA and labeled with Cy3 using the one-color Quick Amp Labeling Kit (Agilent). Hybridization was performed with $1.65 \mu \mathrm{g}$ of labeled cDNA per array at a temperature of $65^{\circ} \mathrm{C}$ overnight. An Agilent G2565CA DNA microarray scanner was used to scan the arrays at a resolution of $5 \mu \mathrm{m}$. The Feature Extraction Software 9.5.3.1 was then used to process and analyze array images. The software returns a series of spot quality measures to evaluate the quality and reliability of spot intensity estimates. The raw data were analyzed using GeneSpring GX 10.0 (normalization: shift to 75.0 percentile, baseline transformation: median of all samples). The normalized data were filtered to exclude probes flagged "absent" in all samples. The remaining probes were tested for statistical significance of expression using a two sample t-test (unpaired) with an asymptotic p-value computation and a p-value cut-off of 0.05 . Multiple testing correction was performed according to Benjamini-Hochberg (Benjamini and Hochberg, 1995; p-value cut off of 0.05). The cut off for the fold change is $\geq 2\left(1 \log _{2}\right)$ up- or down-regulation.

\section{Protein Extraction and Immunoblotting}

Confluent cell monolayers were lysed and homogenized in $25 \mathrm{mM}$ Tris- $\mathrm{HCl}$, pH 7,5, containing 0,1 M NaCl, 1\% NP-40, 10 mM EDTA, 1 mM PEFA-Bloc, $1 \%$ protease inhibitor cocktail and $1 \%$ phosphatase inhibitor cocktail (Calbiochem, Darmstadt, Germany). The culture media were collected and $10 \mathrm{mM}$ EDTA, $1 \mathrm{mM}$ PEFA-Bloc were added. The protein 
content was determined with a micro Lowry assay (DC Protein Assay, Bio-Rad, Munich, Germany). For immunoblotting, equal amounts of proteins were separated on $8 \%, 10 \%$ or $12 \%$ SDS-PAGE under reducing conditions and transferred to nitrocellulose membranes. The membranes were incubated with primary antibodies overnight at $4^{\circ} \mathrm{C}$, followed by incubation with secondary antibodies (Supplementary Table 2) for 2 hours. Visualization was with the ECL Plus system (Amersham, Freiburg, Germany). Band intensities were quantified with Gel-Pro Analyzer software (MediaCybernetics, Inc., Bethesda, MD, USA).

\section{$\underline{\text { ELISA }}$}

For analysis of IL-20 and IL-24 levels secreted into media by NK and KSK under normal culture conditions and after UVB irradiation, a sandwich ELISA was performed. The human IL-20 ELISA Development Kit (Peprotech,Hamburg,Germany) was used according to the manufacturer's instructions. For IL-24 ELISA, the monoclonal capture antibody (clone 283161) and the biotinylated detection antibody from R\&D Systems were used. Briefly, Maxisorp 96 well flat bottom plates (Nunc, Roskilde, Denmark) were coated with $0.5 \mu \mathrm{g} / \mathrm{ml}$ of the capture antibodies overnight. All steps were performed at room temperature and between all steps, the wells were washed four times with washing buffer $(0.05 \%$ Tween in $\underline{\text { PBS). Coated wells were blocked for one hour with blocking buffer (1\% BSA in PBS), and }}$ $\underline{\text { thereafter incubated for } 3 \text { hours with } 100 \mu l \text { of sample and standard (serial dilutions of }}$ $\underline{\text { recombinant IL-20 and IL-24, respectively). Detection was performed with } 0.25 \mu \mathrm{g} / \mathrm{ml} \text { of the }}$ detection antibodies, followed by avidin-HRP-conjugate and OPD-substrate. Optical density $\underline{\text { was measured at } 450 \mathrm{~nm} \text { with a reference at } 650 \mathrm{~nm} \text { over } 30 \mathrm{~min} \text { in } 5 \text { min intervals in a Tecan }}$ reader (Tecan, Austria). IL-20 and IL-24 levels in media were calculated based on the $\underline{\text { standard curves and normalized to the total protein amount in the corresponding lysates. }}$ 


\section{Morphological Analyses and Immunofluorescence Staining}

Dermatohistopathology, immunohistochemistry and indirect immunofluorescence (IIF) were performed using standard techniques (Herz, et al., 2006). Briefly, for IIF, skin cryosections were fixed with acetone, incubated with $0.1 \%$ BSA / TBS for 30 minutes and then with primary antibodies over night (Supplementary Table 2).

For morphological analysis, fibroblasts were grown on 4 well glass chamber slides (Nunc, Langenselbold, Germany) coated with $40 \mu \mathrm{g} / \mathrm{ml}$ collagen I overnight. They were fixed with $2 \%$ paraformaldehyde in PBS for 15 minutes, permeabilized with $0.1 \%$ Triton X-100 and subjected to IIF staining with antibodies to SMA conjugated with Cy3 and TRITCconjugated phalloidin. The chamber slides were mounted in DAKO medium (Dako Cytomation, Hamburg, Germany), observed with epifluorescence microscopy (Zeiss Axio Imager, Zeiss, Germany), and the images were captured using Zeiss internal software. The fluorescence signal was quantified using the image processing software Image J (http://rsbweb.nih.gov/ij/docs/index.html), after background subtraction.

\section{Contraction of Collagen Gels}

The collagen gel contraction assays were performed as described (Zhang, et al., 2006), with minor modifications. Briefly, NF and KSF were seeded at a density of $1.5 \times 10^{5}$ cells $/ \mathrm{ml}$ into $60 \mathrm{~mm}$ bacteriological plates (4 ml/dish) in DMEM supplemented with $10 \% \mathrm{FCS}$, sodium ascorbate $(50 \mu \mathrm{g} / \mathrm{ml})$ and containing $0.60 \mathrm{mg} / \mathrm{ml}$ of acid-extracted collagen I from rat tails. The cultures were placed at $37^{\circ} \mathrm{C}$ to allow collagen polymerization, and gradual contraction was monitored by measuring gel diameter of triplicate setups at successive time points up to 72 hours.

\section{$\underline{\text { Statistical Analysis }}$}


The significance of differences was determined using Student's test or ANOVA (for Fig. 5) with a statistical software in GraphPad Prism. In figures $2 \mathrm{~B}, 3 \mathrm{~A}, 4 \mathrm{C}$ and $5 \mathrm{~A}$ and $\mathrm{B}$, control $\underline{\text { samples (untreated NK or NF, respectively) were set to 1, all other samples were indicated as }}$ fold change compared to control. 


\section{Results}

\section{Soft Tissue Fibrosis in Adults with KS}

Nine patients with known FERMT1 mutations were included in this study. Their age, mutations and phenotypic features indicating fibrosis in skin and mucous membranes are summarized in Table 1. Patients 1 - 4, 6 - 8 have been described in detail before (Has, et al., 2008a; Has, et al., 2006; Has, et al., 2008b; Herz, et al., 2006; Kern, et al., 2007; Mansur, et al., 2007). Importantly, at the time of presentation and skin biopsy, none had blisters, wounds, or skin fragility. Three individuals were children of $\leq 10$ years of age (patients 1,4 and 5 ). Interestingly, they showed no clinical signs of fibrosis of the skin or mucous membranes. In contrast, adults aged 20 - 32 years (patients 2, 3, 6-9) exhibited symptoms indicative of soft tissue fibrosis, including webbing and contractures of the fingers, pseudoainhum (Fig. 1A), poikiloderma (Fig. 1B,C), microstomy (Fig. 1B), esophageal stenosis, ectropion, urethral stenosis, and fusion of labia majora and minora. Patient 6 had been previously diagnosed with systemic sclerosis, but was reclassified as KS after disclosure of the FERMT1 mutation.

Dermatopathology of a biopsy obtained from sun protected skin on the trunk of patient 8 revealed changes characteristic of KS: epidermal atrophy, micro-blisters, pigmentary incontinence, occasional perivascular melanin deposits and dilated blood vessels (not shown). Elastica van Gieson staining demonstrated a dramatic reduction of elastic fibres in the dermis and their replacement with non-elastic connective tissue (Fig. 1D and E), a finding typical of soft tissue fibrosis.

\section{KS Keratinocytes Express Increased Amounts of Cytokines and Growth Factors}

To dissect the particular contribution of keratinocytes to the initiation of fibrosis, oligonucleotide microarrays were used to compare the expression patterns in NK and KSK. 
These revealed significant upregulation of IL-24 (23.4 fold), IL-20 (17.4 fold), TGFB2 (6.5 fold) and IL1F5 (2.9 fold) in KSK. The upregulation was confirmed with both semiquantitative RT-PCR and RTqPCR using two different RNAs extracted from independent NK and KSK cultures, and RNA from primary keratinocytes of patients 1 and 8 (Fig. 2A and B). In addition, the mRNA levels of PDGFB and CTGF were analyzed by the $\underline{\text { above PCR techniques; both were increased in immortalized and primary KSK, as compared }}$ to their controls (Fig. 2A). The expression of TGFB1 was also analyzed, but no significant difference was observed.

\section{KS Keratinocytes Respond to Cell Stress by Expressing IL-20 and IL-24}

Both IL-20 and IL-24 are constitutively expressed in keratinocytes and, therefore, may have a role in epidermal homeostasis (He and Liang, 2010). In KS, the homeostasis is presumably perturbed by fragility of basal epidermal keratinocytes and subsequent cell stress. Therefore, we used three methods to induce cellular stress in vitro and tested its effects on the expression of the two cytokines. Treatment of cultured keratinocytes with $\mathrm{CoCl}_{2}$, which $\underline{\text { mimics hypoxia and with UVB irradiation clearly induced expression of IL-20 and IL-24 in }}$

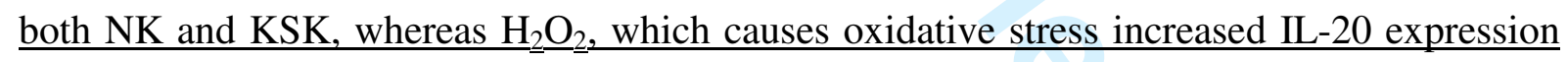
in KSK (Fig. 3A). Intriguingly, the induction was stronger in KSK than in NK, and IL-20 was stronger influenced than IL-24. To confirm these results on protein level, IL-20 and IL-24 were quantified in keratinocyte media by ELISA (Fig. 3B). IL-20 was 2.6 fold (156 \pm 4 versus $\underline{60 \pm 9 \mathrm{pg} / 100 \mu \mathrm{g} \text { protein, } \mathrm{p}<0.001) \text {, and IL-24 was } 5.3 \text { fold }(41 \pm 12 \text { versus } 219 \pm 42}$ $\mathrm{pg} / 100 \mu \mathrm{g}$ protein) increased in KSK media compared to NK media, under normal cell culture $\underline{\text { conditions. Moreover, after UVB irradiation, both cytokines were significantly elevated in }}$ $\underline{\text { KSK, compared to NK media (IL-20: } 276 \pm 13 \text { versus } 86 \pm 11, \mathrm{p}<0.001 \text {; IL-24: } 351 \pm 35}$ versus $74 \pm 37, \mathrm{p}<0.05)$. 


\section{Fibroblasts Are Target Cells for IL-20 and IL-24}

It was unclear whether dermal cells can respond to signals mediated by keratinocytederived IL-20 and IL-24. The common receptors for IL-20 and IL-24, type I composed of IL20R1 / IL20R2 and type II composed of IL22R1 / IL20R2 chains are expressed in keratinocytes, but not in immune cells (Commins, et al., 2008). Now we show that also fibroblasts express the type I receptor complex (Fig. 4A). The complex is functional, since stimulation of both NF and KS fibroblasts (KSF) with IL-20 and IL-24 led to phosphorylation of STAT3 (Fig. 4B). In a control experiment, blocking antibodies to both cytokines prevented the phosphorylation (not shown). These observations indicated that IL-20 and IL-24 secreted by keratinocytes may act both in an autocrine and in a paracrine manner. The paracrine epithelial-to-mesenchymal communication was also suggested by the fact that treatment of

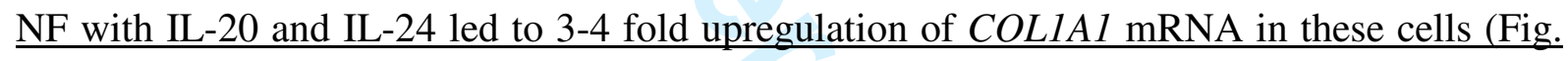
4C), thus directly connecting these interleukins to synthesis of collagen $I$ in dermal fibroblasts.

\section{KS Fibroblasts Exhibit Characteristics of Activated Fibroblasts}

Next, primary early passage KSF from patients 1,2 and 3 were compared with primary NF from age-matched controls. Semiquantitative RT-PCR analysis demonstrated that both cell types expressed similar amounts of kindlin- 2 and $\alpha 1, \alpha 2$ and $\beta 1$ integrin subunits, but had no detectable expression of kindlin-1 (not shown). Similarly, adhesion and proliferation of both cell types did not differ significantly (not shown). However, KSF were morphologically distinguishable in that they had larger surface areas than NF (mean surface area of all NF $2145 \mu \mathrm{m}^{2} \pm 1233$ versus all KSF $4796 \mu \mathrm{m}^{2} \pm 3308, \mathrm{p}<0.0001$ ), and exhibited increased SMA positive stress fibres (not shown). Subsequently, immunoblot analysis 
demonstrated that KSF contained 2.5-4 fold higher SMA levels and secreted significantly more collagen I and tenascin $\mathrm{C}$ than NF (Fig. 5A-C), both findings indicating an activated fibroblast phenotype consistent with the differentiation to myofibroblasts (Kalluri and Zeisberg, 2006; Tomasek, et al., 2002).

Functionally, KSF contracted collagen gels stronger than NF (Fig. 5D). The fibroblastpopulated collagen gels represent a well accepted in vitro model for cell-matrix interactions during wound contraction and fibrotic processes (Dallon and Ehrlich, 2008). They were used to delineate the behaviour of the cells in a more in vivo-like environment. Gel contraction generally depends on cell contraction, cell tractional forces related to cell locomotion, and initial cell elongation and spreading (Dallon and Ehrlich, 2008; Ehrlich, et al., 1989). In accordance with their activated phenotype, fibroblasts of all three KS patients reduced the size of collagen lattices stronger than their normal counterparts, as seen in fibrotic processes (Tse, et al., 2004; Clark, et al., 1989).

\section{$\underline{\text { KSK Conditioned Medium Induces Collagen I and Tenascin C Expression in NF }}$}

$\underline{\text { To assess the effects of soluble factors secreted by KSK on NF in vitro, NF were }}$ cultivated for up to $48 \mathrm{~h}$ in the presence of conditioned media collected either from KSK or $\underline{\text { NK. Interestingly, NF treated with KSK media, secreted about } 1.5 \text { fold more collagen I than }}$ $\underline{\mathrm{NF}}$ treated with NK media, whereas tenascin C, which was present at low levels in NF treated with NK media, was strongly induced by KSK media (Fig. 6). Fibronectin expression and $\underline{\text { secretion were not influenced. This relatively small increase in collagen I, and the presence of }}$ $\underline{\text { tenascin } \mathrm{C} \text { are consistent with a slowly progressive fibrosis, as observed in KS. }}$

\section{Inflammation and Dermal Fibrosis in KS Skin in vivo}


To validate the in vitro data, we analysed skin samples of nine KS patients and found similar abnormalities in all of them. In addition to the general increase of non-elastic connective tissue in the dermis (Fig. 1E), there was strong deposition of tenascin-C beneath the basement membrane, irrespective of age of the patient or the site of the skin biopsy (Fig. 7A,B). Further, SMA was present in the papillary dermis of KS patients, not only in the blood vessels but also in dermal cells, confirming the presence of myofibroblasts (Fig. 7A,B). Inflammatory mediators, such as CD68, F4/80 and IL-10 positive macrophages were present in the dermis of all KS patients irrespective of age and site of the biopsy (Fig. 7C,D). Quantification demonstrated that SMA expression increased with age, whereas the infiltration with CD68 positive macrophages was similar in all patients (not shown). In contrast, number and distribution of lymphocytes and granulocytes was similar in KS and control skin, as shown by staining with several cell-type specific antibodies (not shown). Importantly, three key markers of fibrosis, IL-6, TGF- $\beta 1$, and CTGF were found in the dermis of KS patients, but not of controls (Fig. 7E-J). Interestingly, there was a strong expression of TNFa in KS skin (Fig. 7K,L). 


\section{Discussion}

By demonstrating that dermal changes in KS are a consequence of primary kindlin-1 deficiency in keratinocytes we suggest paracrine epithelial-mesenchymal signals as novel phenotype modifiers in this disease (Fig. 8). FERMT1 mutations lead to upregulation of several cytokines in keratinocytes, similar to cytokine secretion induced by certain keratin mutations in epidermolysis bullosa simplex (Coulombe, et al., 2009; Roth, et al., 2009). In both diseases the mutated proteins, kindlin-1 and keratin 5, are expressed only in epidermal keratinocytes and are associated with maintenance of functional cytoskeletal structures. As a consequence, their pathological alterations cause cell fragility and stress.

In the present study, expression array data disclosed IL-20 and IL-24 as major upregulated genes in KS keratinocytes, and the findings were validated with RTqPCR and confirmed on protein level by ELISA. Thus far, little has been known about the functions of these cytokines in the skin. A recent study reported their induction after skin injury (Roupe, et al., 2010), and previous investigations suggested regulation of these interleukins through stress induced pathways (Chen and Chang, 2009; Hunt, et al., 2006; Otkjaer, et al., 2010; Otkjaer, et al., 2007). To corroborate this in KS, we used three different well-established methods - hypoxia, oxidative stress and UVB irradiation - to induce cell stress in normal and KS keratinocytes and showed that stress enhances expression and secretion of IL-20 and IL24 by KS cells. The upregulation was stronger in KS keratinocytes, presumably because their pre-existing cytoskeletal abnormalities aggravated the stress. These results extend observations on stimulation of IL-20 upon hypoxia (Chen and Chang, 2009) and UVB irradiation (Hunt, et al., 2006). Both IL-20 and IL-24 expression is dependent on p38 MAPK (Otkjaer, et al. 2010; Otkjaer, et al., 2007), which is increased in KS cells (own unpublished results). 
Our data suggest that dermal fibroblasts are targets for IL-20 and IL-24. They have functional receptors for both cytokines, as shown by increased STAT3 phosphorylation in fibroblasts after treatment with IL-20 and IL-24. Interestingly, the cytokines also directly induced collagen I expression in fibroblasts. However, this is likely to be only one contributor to the dermal changes in $\mathrm{KS}$, since fibrosis is a complex, orchestrated process with many players in vivo. Little is known about IL1F5, a member of the interleukin 1 cytokine family. This cytokine has been shown to specifically inhibit the activation of NF-kappaB induced by interleukin 1 family, member 6 (Blumberg, et al., 2007), but its contribution to KS phenotypes remains to be established.

A major mediator of fibrotic processes, TGF- $\beta 2$, was among the factors upregulated in KS keratinocytes. Its role in KS skin may be similar to that in airway epithelium, where epithelial-derived TGF- $\beta 2$ modulates the subepithelial extracellular matrix and mediates repair responses to epithelial injury (Thompson, et al., 2006). Epithelial-mesenchymal interactions mediated by soluble factors can also occur in the other direction. An example of mesenchyme-to-epithelium signals is modulation of collagen VII synthesis in epidermal keratinocytes. During tissue repair, the expression of this essential dermal-epidermal adhesion protein is stimulated by mesenchyme-derived TGF- $\beta$ (Konig and Bruckner-Tuderman, 1991).

Interestingly, dermal fibrosis similar to $\mathrm{KS}$ has been observed in mice with keratinocyte-restricted deletion of integrin beta-1, which exhibited basement membrane defects, macrophage infiltration, increased expression of TGF- $\beta 1$, CTGF and tenascin-C, and dermal fibrosis (Brakebusch, et al., 2000). In that case the molecular mechanisms were not explored. In light of our present findings and the fact that kindlin-1 is an intracellular ligand and modulator of $\beta 1$ integrin, it is likely that $\beta 1$ integrin deficiency causes epidermal fragility and cell stress leading to perturbed epithelial-mesenchymal interactions and fibrosis in the dermis. 
A significant contribution to soft tissue fibrosis comes from chronic inflammatory processes, which are known to be the cause of fibrosis in various tissues and organs (Wynn, 2008). Our prediction is that in KS chronic mild inflammation is followed by progressive fibrosis in the dermis, presumably as a result of the expression and activation of TGF- $\beta$, CTGF and IL-6 (Hinz, 2007). These cytokines play an important role in the induction of extracellular matrix synthesis by fibroblasts and thus in the pathogenesis of the fibrotic diseases (reviewed by Hinz, 2007; Wynn, 2008). In KS, the inflammation seems to have two components: on one hand, the secretion of cytokines by kindlin-1 null keratinocytes and, on the other hand, the infiltration with macrophages. The massive upregulation of tenascin $\mathrm{C}$, which is not seen in normal skin (Schenk, et al., 1995), is likely to reflect continuous tissue and basement membrane remodelling processes in KS. It is difficult to establish the precise contribution of each pathogenic factor. Probably, cumulative effects maintain profibrotic loops leading to a slowly progressive fibrosis. The clinical consequences are extensive skin and mucous membrane lesions and slight stiffening of the skin, similar to scleroderma, a complex, acquired connective tissue disorder characterized by excessive extracellular matrix deposition in the dermis (Abraham, et al., 2009; Varga and Abraham, 2007). Incidentally, patient 6 of the present study had received immunosuppressive drugs as scleroderma treatment for several years, before KS was diagnosed. A similar situation was reported recently in an other KS patient (Has, et al., 2010). The fact that cytokine-mediated alterations of epithelial-mesenchymal signals have now been identified as phenotype modifiers in KS will improve understanding of the molecular disease mechanisms, prevent unnecessary therapeutic exposures and lay a basis for design of novel biological therapies.

\section{Acknowledgments}


This work was supported by a grant from DFG (HA 5663/1-1) to C.H. and L.B.-T., by the International Kindler Syndrome Network Kindlernet grant from ERANET, project Nr. 01GM0812, by the Network Epidermolysis bullosa grant from the Federal Ministry for Education and Research (BMBF), project 9 (L.B.-T.), by the Excellence Initiative of the German Federal Governments and the Freiburg Institute for Advanced Studies FRIAS (H.B., M.B., L.B.-T.). 


\section{Figure Legends}

Figure 1. The fibrotic phenotype in KS skin. A: Dorsal aspect of the left hand of the 20 yearold patient 6 showing skin atrophy, erythema and scaling, webbing of the fingers, severe nail dystrophy and pseudoainhum (fibrotic ring) of the fifth finger. B: The face of patient 6 resembles "scleroderma face" with tight skin, pointed nose, microstomy and teleangiectasia. C: Poikiloderma of the neck of the 28 year-old patient 9. D: Elastica van Gieson staining of control skin reveals abundant dark elastic fibers. E: Elastica van Gieson staining of the skin of the 27 year-old patient 8 demonstrates drastic reduction and abnormal aggregation of elastic fibres in the upper dermis. Bar for D and $\mathrm{E}=100 \mu \mathrm{m}$

Figure 2. Upregulation of cytokines and growth factors in KS keratinocytes. After expression microarrays had suggested upregulation of cytokines in KSK, the findings were validated with RT-PCR and RTqPCR. A: Agarose gel electrophoresis of semiquantitative RTPCR products on total RNA from NK and KSK cell lines (left panel) and from primary NK and primary KSK of patient 8 (right panel). B: Relative quantification of IL-20, IL-24, IL1F5, TGFB2, CTGF and PDGF mRNAs in NK and KSK by RTqPCR. The expression of all these genes is significantly increased in KSK in the same range as those obtained in the microrray analyses.

Figure 3. Cell stress triggers upregulation of IL-20 and IL-24 in keratinocytes. A: NK and KSK cell lines were treated with $1000 \mu \mathrm{M} \mathrm{CoCl}_{2}(+)$ or with PBS (-) for $1 \mathrm{~h} ; 1000 \mu \mathrm{M} \mathrm{H} \mathrm{H}_{2} \mathrm{O}_{2}$ (+) or with PBS (-) for $4 \mathrm{~h}$; irradiated with $60 \mathrm{~mJ} / \mathrm{cm}^{2} \mathrm{UVB}(+)$ or not irradiated (-). Gene expression was quantified by RTqPCR. For each condition three RNAs isolated and $\underline{\text { transcribed independently were submitted in duplicate to the RTqPCR reaction. Values of }}$ 
untreated NK were arbitrarily set to 1 , all other samples were indicated as fold change compared to control. B: The graphs show the amount of IL-20 (left) and IL-24 (right) in the culture media of NK and KSK, under normal culture conditions, and after UVB irradiation as measured by sandwich ELISA.

Figure 4. Fibroblasts are target cells for IL-20 and IL-24. A: Semiquantitative RT-PCR shows expression of receptor chains IL20R1, IL20R2 and IL22R1 in NF, KSF, NK and KSK. B: NF were treated with (+) or without (-) IL-20 or IL-24 for 20 minutes, and the cells were lysed and subjected to immunoblotting with antibodies to phosphoSTAT3 and total STAT3. The substantial increase of phosphoSTAT3 upon IL-20 or IL-24 stimulation indicates the functionality of the IL-20, IL-24 receptor complexes. C: Expression of COL1A1 in fibroblasts is induced by IL-20 and IL-24. NF were treated with $10 \mathrm{ng} / \mathrm{ml}$ of IL-20 and IL-24. At the indicated time points, total RNA was isolated and RTqPCR was performed to assess the expression of the COL1A1 gene. The HPRT1 and $18 \mathrm{~s}$ genes as housekeeping genes were used for normalization of loading.

Figure 5. KSF have an activated phenotype consistent with differentiation to myofibroblasts, as shown by increased synthesis of SMA collagen I and tenascin C, and by enhanced collagen gel contraction. A: The upper panel shows an immunoblot with lysates of fibroblasts of patient 1 (KSF1) and its corresponding control NF1, and anti-SMA or anti-GAPDH antibodies. The lower panel shows the quantification of the SMA band densities in immunoblots of fibroblasts of patients 1-3 (KSF1, KSF2, KSF3), and the NF1-3 as controls. The mean values and SD are shown; *, p<0.05; **, p $<0.01$ B: The upper panel shows an immunoblot with medium of fibroblasts of patient 2 (KSF2) and its corresponding control NF2, and anti-collagen I antibodies. The lower panel shows the quantification of the collagen 
I band densities from immunoblot analyses of fibroblasts of patients 1-3 (KSF1, KSF2, KSF3), and the NF1-3. The mean values and SD are shown; *, p<0.05; **, p<0.01. C: Representative immunoblots demonstrate that NF barely express tenascin C, whereas KSF produce and secrete large amounts of this protein. D: Collagen gel contraction assays show increased gel contraction by KSF, a mechanism typically associated with myofibroblasts with higher cellular contraction (Dallon et al . 2008). Representative examples of KSF1 and NF1 are shown (fibroblasts from the other two KS patients exhibited similar behaviour) in the upper panel. The lower panel displays the quantification of the gel areas of all patients and $\underline{\text { controls (for all time points } \mathrm{p}<0.01 \text { ). }}$

Figure 6. Deposition of collagen I and production of tenascin C are induced by treatment of $\underline{\text { NF with conditioned KSK media. Representative immunoblots of media and lysates of NF }}$ treated for 24 and 48 hours with conditioned media from either NK or KSK. Blots with antibodies to collagen I, tenascin C and fibronectin are shown. Loading was verified with antibodies to GAPDH.

Figure 7. KS skin in situ is marked with inflammation and fibrosis. IIF analysis of normal human $(\mathrm{NH})$ and $\mathrm{KS}$ skin was performed. A, B: Deposition of tenascin-C (green) beneath the dermal-epidermal basement membrane, combined with presence of SMA (red)-positive myofibroblasts in the superficial dermis in KS skin. C, D: CD68 positive macrophages (green) are abundant in KS skin, but not in control skin. A number of macrophages are IL-10positive (yellow in merge image). E, F: Abundant IL-6 in the dermis in KS skin, but not in control skin. G, H: The presence of active TGF- $\beta 1$ is increased in KS skin, as compared to normal skin. I, J: The downstream effector of TGF- $\beta 1$, CTGF, is found in KS skin but not in normal skin. In panels D, F, H and J, insets represent 2-fold magnifications of the areas 


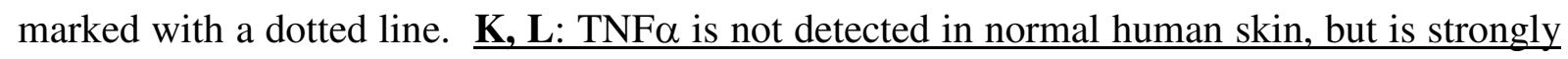
expressed in KS skin, mainly in the epidermis. Nuclei are stained with DAPI (blue). Bar for all panels $=50 \mu \mathrm{m}$.

Figure 8. A schematic model for the pathogenesis of fibrosis in KS. As the background to delineate the microanatomical structures, immunohistochemical staining of KS skin with antiCD68 antibodies was used. CD68 positive macrophages are labelled in red and nuclei in blue (E, epidermis; D, dermis). Kindlin-1 deficient keratinocytes respond to cell stress by secreting cytokines and growth factors, including IL-20, IL-24, IL1F5, TGF- $\beta 2$, CTGF and PDGFB. These target fibroblasts and activate them to express SMA and to increase the production of collagen I. Macrophages are recruited and express IL-10, a marker for regulatory macrophages (Mosser and Edwards, 2008). TGF- $\beta 1$, CTGF and IL-6 stimulate fibroblasts to differentiate into myofibroblasts and to synthesize more extracellular matrix proteins, including tenascin-C and collagen I. As epithelial-mesenchymal interactions are bidirectional, it is likely that the altered dermal environment also influences keratinocyte functions, thus contributing to the development of the fibrotic skin phenotype over many years, as seen in adult KS patients. 


\section{References}

Abraham DJ, Krieg T, Distler J, Distler O. 2009. Overview of pathogenesis of systemic sclerosis. Rheumatology (Oxford) 48 Suppl 3:iii3-7.

Blumberg H, Dinh H, Trueblood ES, Pretorius J, Kugler D, Weng N, Kanaly ST, Towne JE, Willis CR, Kuechle MK and others. 2007. Opposing activities of two novel members of the IL-1 ligand family regulate skin inflammation. J Exp Med 204(11):2603-14.

Brakebusch C, Grose R, Quondamatteo F, Ramirez A, Jorcano JL, Pirro A, Svensson M, Herken R, Sasaki T, Timpl R and others. 2000. Skin and hair follicle integrity is crucially dependent on beta 1 integrin expression on keratinocytes. EMBO $\mathrm{J}$ 19(15):3990-4003.

Chen WY, Chang MS. 2009. IL-20 is regulated by hypoxia-inducible factor and up-regulated after experimental ischemic stroke. J Immunol 182(8):5003-12.

Clark RA, Folkvord JM, Hart CE, Murray MJ, McPherson JM. 1989. Platelet isoforms of platelet-derived growth factor stimulate fibroblasts to contract collagen matrices. $\mathbf{J}$ Clin Invest 84(3):1036-40.

Commins S, Steinke JW, Borish L. 2008. The extended IL-10 superfamily: IL-10, IL-19, IL20, IL-22, IL-24, IL-26, IL-28, and IL-29. J Allergy Clin Immunol 121(5):1108-11.

Coulombe PA, Kerns ML, Fuchs E. 2009. Epidermolysis bullosa simplex: a paradigm for disorders of tissue fragility. J Clin Invest 119(7):1784-93.

Dallon JC, Ehrlich HP. 2008. A review of fibroblast-populated collagen lattices. Wound Repair Regen 16(4):472-9.

Ehrlich HP, Buttle DJ, Bernanke DH. 1989. Physiological variables affecting collagen lattice contraction by human dermal fibroblasts. Exp Mol Pathol 50(2):220-9.

Fine JD, Eady RA, Bauer EA, Bauer JW, Bruckner-Tuderman L, Heagerty A, Hintner H, Hovnanian A, Jonkman MF, Leigh I and others. 2008. The classification of inherited epidermolysis bullosa (EB): Report of the Third International Consensus Meeting on Diagnosis and Classification of EB. J Am Acad Dermatol 58(6):931-50.

Ghaffari A, Kilani RT, Ghahary A. 2009. Keratinocyte-conditioned media regulate collagen expression in dermal fibroblasts. J Invest Dermatol 129(2):340-7.

Has C, Burger B, Volz A, Kohlhase J, Bruckner-Tuderman L, Itin P. 2010. Mild Clinical Phenotype of Kindler Syndrome Associated with Late Diagnosis and Skin Cancer. Dermatology. Epubl

Has C, Herz C, Zimina E, Qu HY, He Y, Zhang ZG, Wen TT, Gache Y, Aumailley M, Bruckner-Tuderman L. 2009. Kindlin-1 Is required for RhoGTPase-mediated lamellipodia formation in keratinocytes. Am J Pathol 175(4):1442-52.

Has C, Ludwig RJ, Herz C, Kern JS, Ussar S, Ochsendorf FR, Kaufmann R, Schumann H, Kohlhase J, Bruckner-Tuderman L. 2008a. C-terminally truncated kindlin-1 leads to abnormal adhesion and migration of keratinocytes. Br J Dermatol 159(5):1192-6.

Has C, Wessagowit V, Pascucci M, Baer C, Didona B, Wilhelm C, Pedicelli C, Locatelli A, Kohlhase J, Ashton GH and others. 2006. Molecular basis of Kindler syndrome in Italy: novel and recurrent Alu/Alu recombination, splice site, nonsense, and frameshift mutations in the KIND1 gene. J Invest Dermatol 126(8):1776-83.

Has C, Yordanova I, Balabanova M, Kazandjieva J, Herz C, Kohlhase J, Bruckner-Tuderman L. 2008b. A novel large FERMT1 (KIND1) gene deletion in Kindler syndrome. J Dermatol Sci 52(3):209-12.

He M, Liang P. 2010. IL-24 transgenic mice: in vivo evidence of overlapping functions for IL-20, IL-22, and IL-24 in the epidermis. J Immunol 184(4):1793-8. 
Herz C, Aumailley M, Schulte C, Schlotzer-Schrehardt U, Bruckner-Tuderman L, Has C. 2006. Kindlin-1 is a phosphoprotein involved in regulation of polarity, proliferation, and motility of epidermal keratinocytes. J Biol Chem 281(47):36082-90.

Hinz B. 2007. Formation and function of the myofibroblast during tissue repair. J Invest Dermatol 127(3):526-37.

Hunt DW, Boivin WA, Fairley LA, Jovanovic MM, King DE, Salmon RA, Utting OB. 2006. Ultraviolet B light stimulates interleukin-20 expression by human epithelial keratinocytes. Photochem Photobiol 82(5):1292-300.

Kalluri R, Zeisberg M. 2006. Fibroblasts in cancer. Nat Rev Cancer 6(5):392-401.

Kern JS, Herz C, Haan E, Moore D, Nottelmann S, von Lilien T, Greiner P, Schmitt-Graeff A, Opitz OG, Bruckner-Tuderman L and others. 2007. Chronic colitis due to an epithelial barrier defect: the role of kindlin-1 isoforms. J Pathol 213(4):462-70.

Konig A, Bruckner-Tuderman L. 1991. Epithelial-mesenchymal interactions enhance expression of collagen VII in vitro. J Invest Dermatol 96(6):803-8.

Lai-Cheong JE, McGrath JA. 2010. Kindler syndrome. Dermatol Clin 28(1):119-24.

Lai-Cheong JE, Tanaka A, Hawche G, Emanuel P, Maari C, Taskesen M, Akdeniz S, Liu L, McGrath JA. 2009. Kindler syndrome: a focal adhesion genodermatosis. Br J Dermatol 160(2):233-42.

Mansur AT, Elcioglu NH, Aydingoz IE, Akkaya AD, Serdar ZA, Herz C, BrucknerTuderman L, Has C. 2007. Novel and recurrent KIND1 mutations in two patients with Kindler syndrome and severe mucosal involvement. Acta Derm Venereol 87(6):563-5.

Moser M, Legate KR, Zent R, Fassler R. 2009. The tail of integrins, talin, and kindlins. Science 324(5929):895-9.

Mosser DM, Edwards JP. 2008. Exploring the full spectrum of macrophage activation. Nat Rev Immunol 8(12):958-69.

Otkjaer K, Holtmann H, Kragstrup TW, Paludan SR, Johansen C, Gaestel M, Kragballe K, Iversen L. 2010. The p38 MAPK regulates IL-24 expression by stabilization of the 3' UTR of IL-24 mRNA. PLoS One 5(1):e8671.

Otkjaer K, Kragballe K, Johansen C, Funding AT, Just H, Jensen UB, Sorensen LG, Norby PL, Clausen JT, Iversen L. 2007. IL-20 gene expression is induced by IL-1beta through mitogen-activated protein kinase and NF-kappaB-dependent mechanisms. J Invest Dermatol 127(6):1326-36.

Roth W, Reuter U, Wohlenberg C, Bruckner-Tuderman L, Magin TM. 2009. Cytokines as genetic modifiers in K5-/- mice and in human epidermolysis bullosa simplex. Hum Mutat 30(5):832-41.

Roupe KM, Nybo M, Sjobring U, Alberius P, Schmidtchen A, Sorensen OE. 2010. Injury is a major inducer of epidermal innate immune responses during wound healing. J Invest Dermatol 130(4):1167-77.

Schenk S, Bruckner-Tuderman L, Chiquet-Ehrismann R. 1995. Dermo-epidermal separation is associated with induced tenascin expression in human skin. $\mathrm{Br} \mathrm{J}$ Dermatol 133(1):13-22.

Thompson HG, Mih JD, Krasieva TB, Tromberg BJ, George SC. 2006. Epithelial-derived TGF-beta2 modulates basal and wound-healing subepithelial matrix homeostasis. Am J Physiol Lung Cell Mol Physiol 291(6):L1277-85.

Tomasek JJ, Gabbiani G, Hinz B, Chaponnier C, Brown RA. 2002. Myofibroblasts and mechano-regulation of connective tissue remodelling. Nat Rev Mol Cell Biol 3(5):349-63.

Tse R, Howard J, Wu Y, Gan BS. 2004. Enhanced Dupuytren's disease fibroblast populated collagen lattice contraction is independent of endogenous active TGF-beta2. BMC Musculoskelet Disord 5(1):41. 
Ussar S, Moser M, Widmaier M, Rognoni E, Harrer C, Genzel-Boroviczeny O, Fassler R. 2008. Loss of kindlin-1 causes skin atrophy and lethal neonatal intestinal epithelial dysfunction. PLoS Genet 4(12):e1000289.

Varga J, Abraham D. 2007. Systemic sclerosis: a prototypic multisystem fibrotic disorder. J Clin Invest 117(3):557-67.

Werner S, Krieg T, Smola H. 2007. Keratinocyte-fibroblast interactions in wound healing. J Invest Dermatol 127(5):998-1008.

Wynn TA. 2008. Cellular and molecular mechanisms of fibrosis. J Pathol 214(2):199-210.

Zhang ZG, Bothe I, Hirche F, Zweers M, Gullberg D, Pfitzer G, Krieg T, Eckes B, Aumailley M. 2006. Interactions of primary fibroblasts and keratinocytes with extracellular matrix proteins: contribution of alpha2beta1 integrin. J Cell Sci 119(Pt 9):1886-95. 

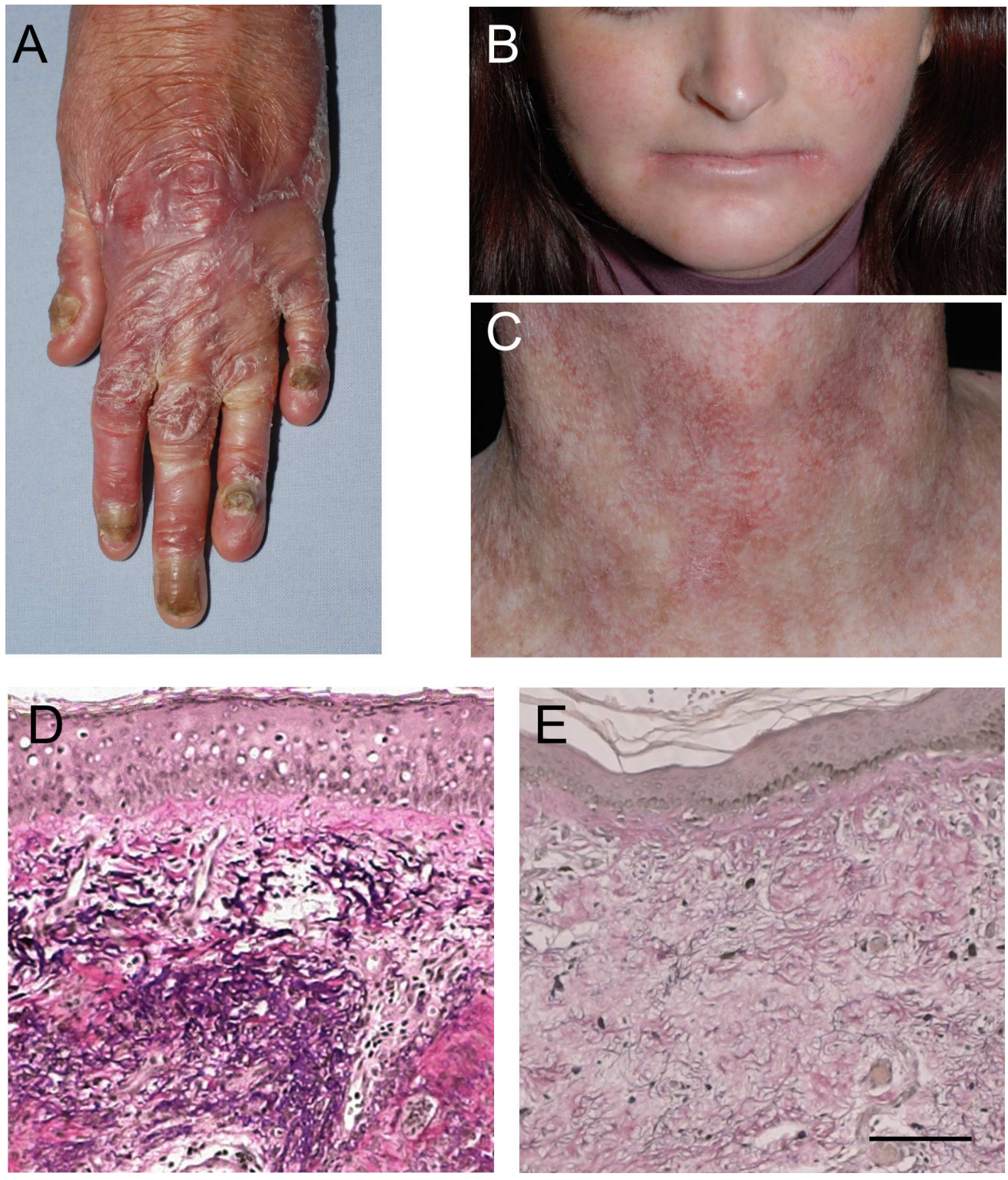

Figure 1. The fibrotic phenotype in KS skin. A: Dorsal aspect of the left hand of the 20 year-old patient 6 showing skin atrophy, erythema and scaling, webbing of the fingers, severe nail dystrophy and pseudoainhum (fibrotic ring) of the fifth finger. B: The face of patient 6 resembles "scleroderma face" with tight skin, pointed nose, microstomy and teleangiectasia. C: Poikiloderma of the neck of the 28 year-old patient 9. D: Elastica van Gieson staining of control skin reveals abundant dark elastic fibers. E: Elastica van Gieson staining of the skin of the 27 year-old patient 8 demonstrates drastic reduction and abnormal aggregation of elastic fibres in the upper dermis. Bar for $D$ and $E=$ $100 \mu \mathrm{m}$ 
B

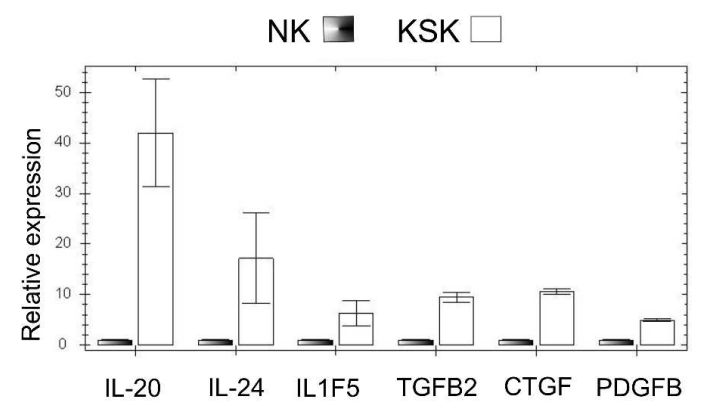

NK KSK

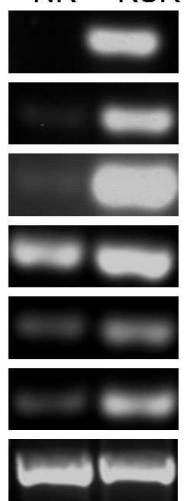

Figure 2. Upregulation of cytokines and growth factors in KS keratinocytes. After expression microarrays had suggested upregulation of cytokines in KSK, the findings were validated with RTPCR and RTqPCR. A: Agarose gel electrophoresis of semiquantitative RT-PCR products on total RNA from NK and KSK cell lines (left panel) and from primary NK and primary KSK of patient 8 (right panel). B: Relative quantification of IL-20, IL-24, IL1F5, TGFB2, CTGF and PDGF mRNAs in NK and KSK by RTqPCR. The expression of all these genes is significantly increased in KSK: IL-20 42-fold, IL-24 17-fold, IL1F5 6.3-fold, TGFB2 9.5-fold, CTGF 10-fold and PDGFB 5-fold. These values are in the same range as those obtained in the microrray analyses. 


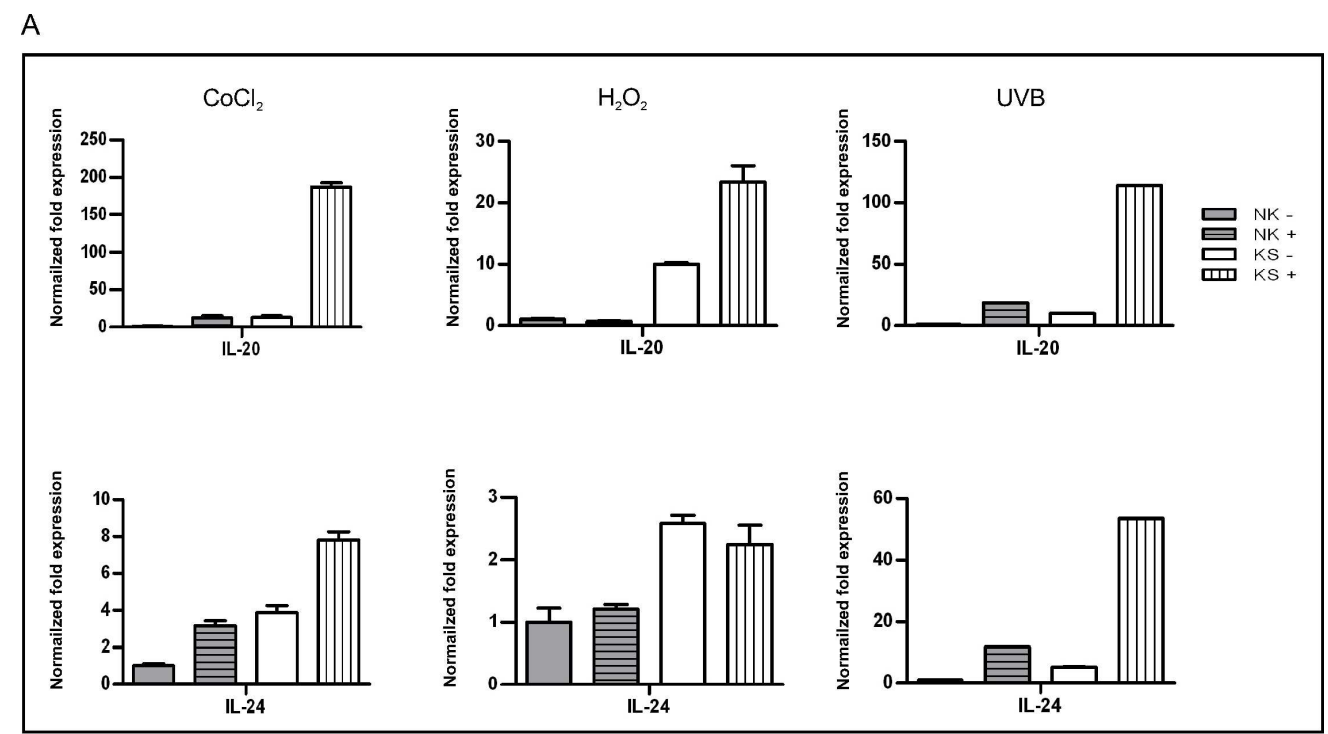

B
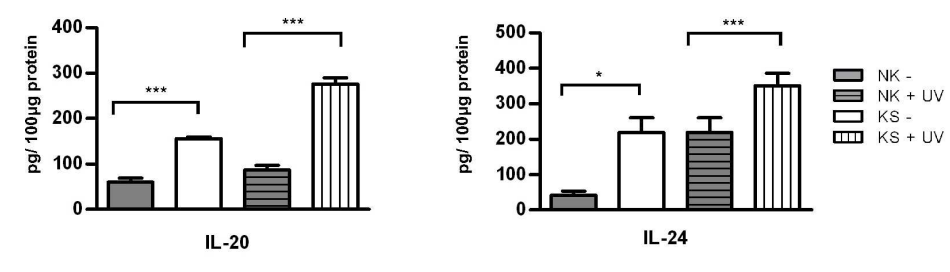

皿 KS + UV

Figure 3. Cell stress triggers upregulation of IL-20 and IL-24 in keratinocytes. A: NK and KSK cell lines were treated with $1000 \mu \mathrm{M} \mathrm{CoCl} 2(+)$ or with PBS (-) for $1 \mathrm{~h} ; 1000 \mu \mathrm{M} \mathrm{H} 2 \mathrm{O} 2(+)$ or with PBS (-) for $4 \mathrm{~h}$; irradiated with $60 \mathrm{~mJ} / \mathrm{cm} 2$ UVB $(+)$ or not irradiated $(-)$. Gene expression was quantified by RTqPCR. For each condition three RNAs isolated and transcribed independently were submitted in duplicate to the RTqPCR reaction. Values of untreated NK were arbitrarily set to 1 , all other samples were indicated as fold change compared to control. B: The graphs show the amount of IL-20 (left) and IL-24 (right) in the culture media of NK and KSK, under normal culture conditions, and after UVB irradiation as measured by sandwich ELISA. 

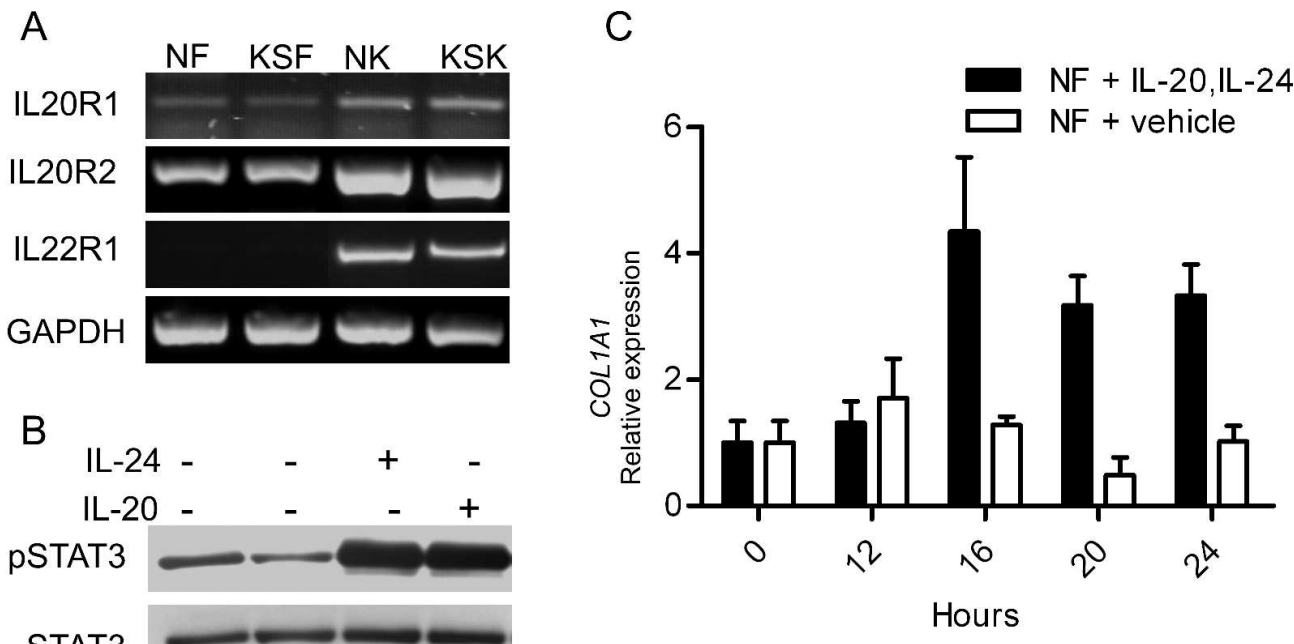

STAT3

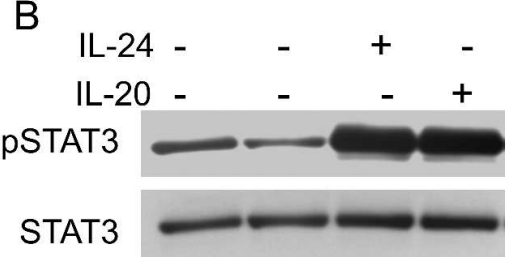

Figure 4. Fibroblasts are target cells for IL-20 and IL-24. A: Semiquantitative RT-PCR shows expression of receptor chains IL20R1, IL20R2 and IL22R1 in NF, KSF, NK and KSK. B: NF were treated with $(+)$ or without (-) IL-20 or IL-24 for 20 minutes, and the cells were lysed and subjected to immunoblotting with antibodies to phosphoSTAT3 and total STAT3. The substantial increase of phosphoSTAT3 upon IL-20 or IL-24 stimulation indicates the functionality of the IL-20, IL-24 receptor complexes. C: Expression of COL1A1 in fibroblasts is induced by IL-20 and IL-24. NF were treated with $10 \mathrm{ng} / \mathrm{ml}$ of IL-20 and IL-24. At the indicated time points, total RNA was isolated and RTqPCR was performed to assess the expression of the COL1A1 gene. The HPRT1 and 18s genes as housekeeping genes were used for normalization of loading. 

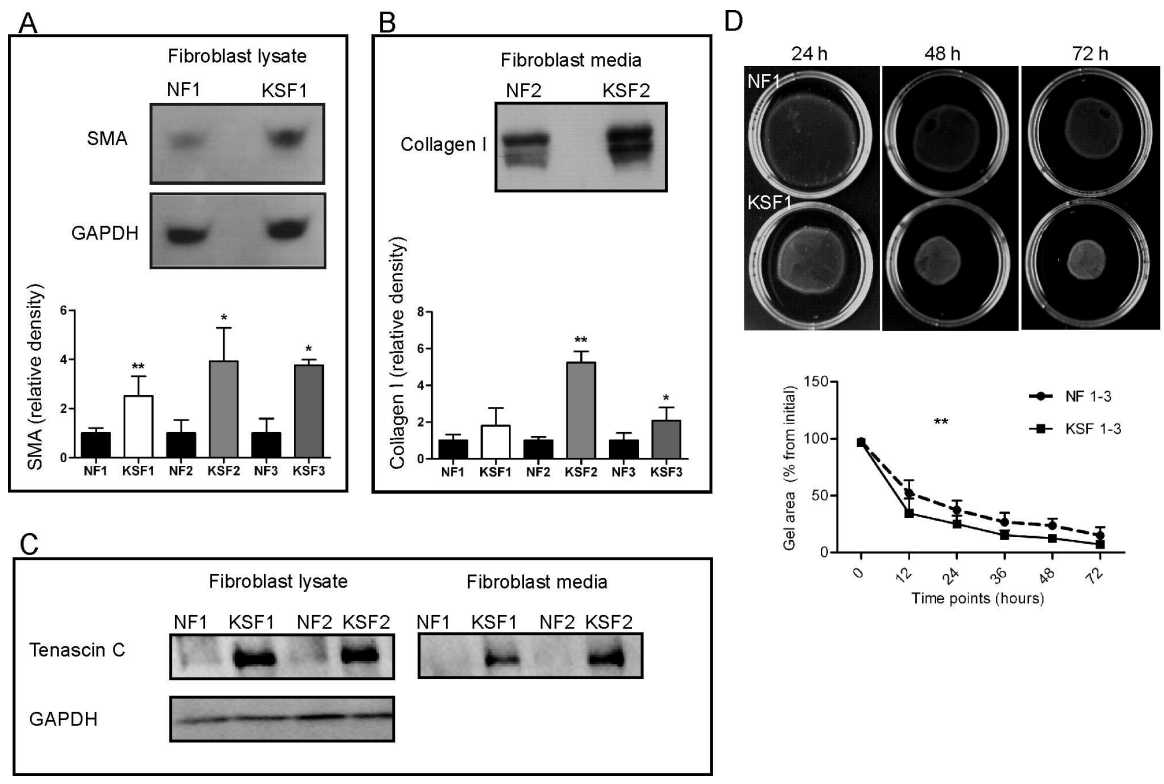

Figure 5. KSF have an activated phenotype consistent with differentiation to myofibroblasts, as shown by increased synthesis of SMA collagen I and tenascin C, and by enhanced collagen gel contraction. A: The upper panel shows an immunoblot with lysates of fibroblasts of patient 1 (KSF1) and its corresponding control NF1, and anti-SMA or anti-GAPDH antibodies. The lower panel shows the quantification of the SMA band densities in immunoblots of fibroblasts of patients 1-3 (KSF1, $\mathrm{KSF} 2, \mathrm{KSF} 3$ ), and the NF1-3 as controls. The mean values and SD are shown; *, p $<0.05$; **, $\mathrm{p}<0.01 \mathrm{~B}$ : The upper panel shows an immunoblot with medium of fibroblasts of patient 2 (KSF2) and its corresponding control NF2, and anti-collagen I antibodies. The lower panel shows the quantification of the collagen I band densities from immunoblot analyses of fibroblasts of patients 13 (KSF1, KSF2, KSF3), and the NF1-3. The mean values and SD are shown; $*, \mathrm{p}<0.05 ; * *, \mathrm{p}<0.01$. $\mathrm{C}$ : Representative immunoblots demonstrate that NF barely express tenascin $\mathrm{C}$, whereas KSF produce and secrete large amounts of this protein. D: Collagen gel contraction assays show increased gel contraction by KSF, a mechanism typically associated with myofibroblasts with higher cellular contraction (Dallon et al . 2008). Representative examples of KSF1 and NF1 are shown (fibroblasts from the other two KS patients exhibited similar behaviour) in the upper panel. The lower panel displays the quantification of the gel areas of all patients and controls (for all time points $\mathrm{p}<0.01)$. 
Figure 6. Deposition of collagen I and production of tenascin C are induced by treatment of NF with conditioned KSK media. Representative immunoblots of media and lysates of NF treated for 24 and 48 hours with conditioned media from either NK or KSK. Blots with antibodies to collagen I, tenascin $\mathrm{C}$ and fibronectin are shown. Loading was verified with antibodies to GAPDH. 

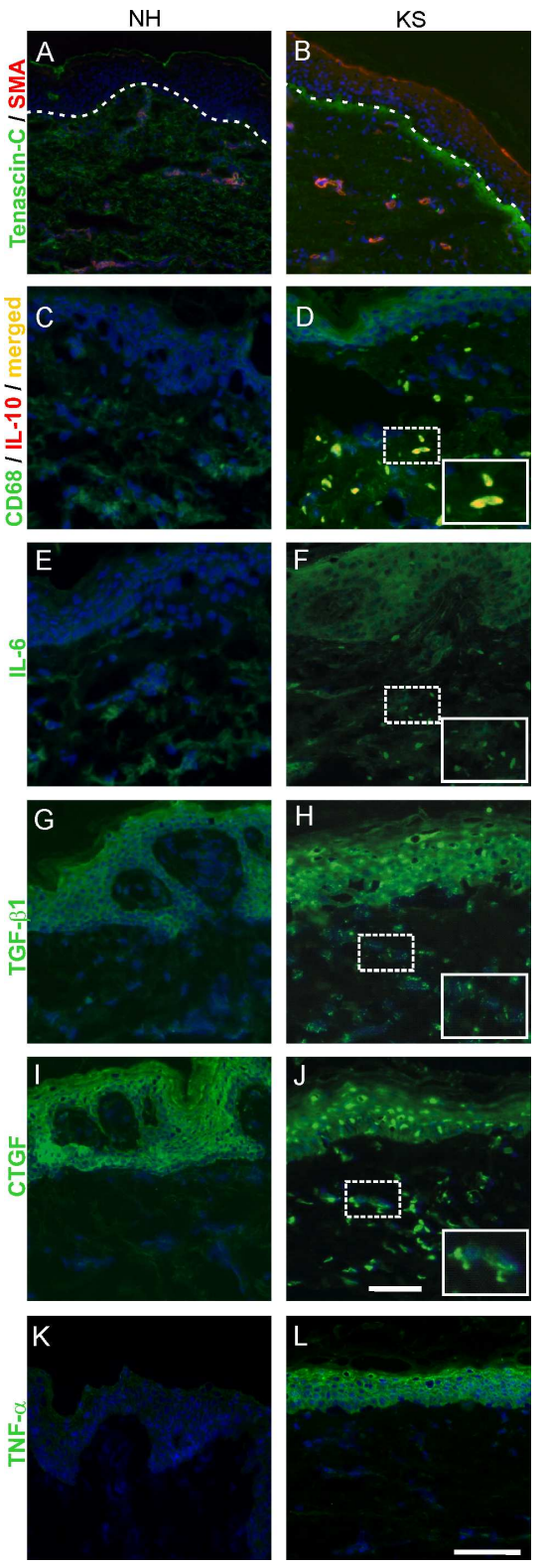

Figure 7. KS skin in situ is marked with inflammation and fibrosis. IIF analysis of normal human

$(\mathrm{NH})$ and KS skin was performed. A, B: Deposition of tenascin-C (green) beneath the dermalepidermal basement membrane, combined with presence of SMA (red)-positive myofibroblasts in the superficial dermis in KS skin. C, D: CD68 positive macrophages (green) are abundant in KS skin, but not in control skin. A number of macrophages are IL-10-positive (yellow in merge image). E, F: Abundant IL-6 in the dermis in KS skin, but not in control skin. G, H: The presence of active TGF- $\beta 1$ is increased in KS skin, as compared to normal skin. I, J: The downstream effector of TGF$\beta 1, C T G F$, is found in KS skin but not in normal skin. In panels $D, F, H$ and J, insets represent 2-fold magnifications of the areas marked with a dotted line. K, L: TNF $\alpha$ is not detected in normal human skin, but is strongly expressed in KS skin, mainly in the epidermis. Nuclei are stained with DAPI (blue). Bar for all panels $=50 \mu \mathrm{m}$. 


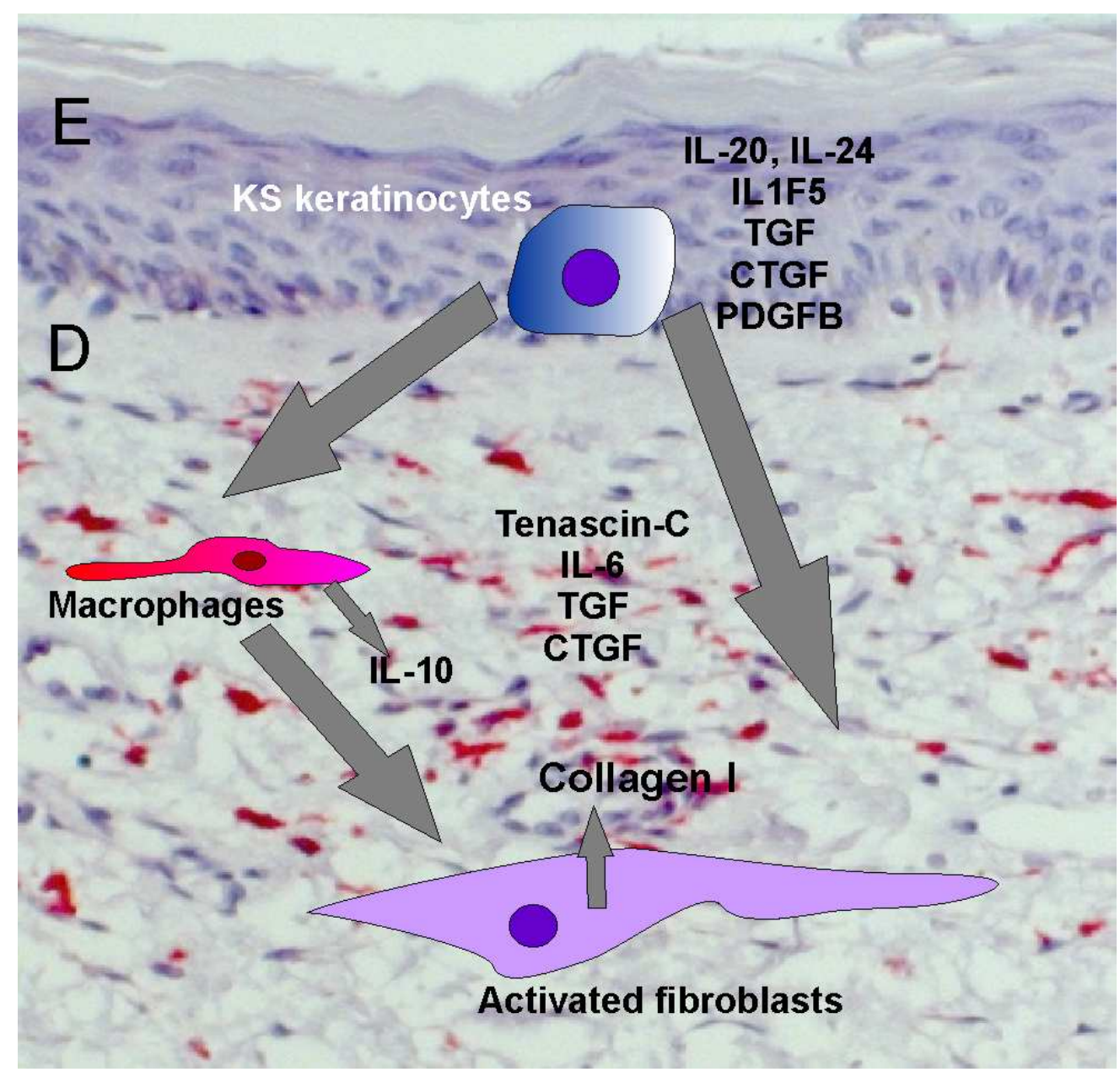

Figure 8. A schematic model for the pathogenesis of fibrosis in KS. As the background to delineate the microanatomical structures, immunohistochemical staining of KS skin with anti-CD68 antibodies was used. CD68 positive macrophages are labelled in red and nuclei in blue ( $E$, epidermis; $D$, dermis). Kindlin-1 deficient keratinocytes respond to cell stress by secreting cytokines and growth factors, including IL-20, IL-24, IL1F5, TGF- $\beta 2$, CTGF and PDGFB. These target fibroblasts and activate them to express SMA and to increase the production of collagen I. Macrophages are recruited and express IL-10, a marker for regulatory macrophages (Mosser and Edwards, 2008). TGF- $\beta 1$, CTGF and IL- 6 stimulate fibroblasts to differentiate into myofibroblasts and to synthesize more extracellular matrix proteins, including tenascin- $\mathrm{C}$ and collagen I. As epithelial-mesenchymal interactions are bi-directional, it is likely that the altered dermal environment also influences keratinocyte functions, thus contributing to the development of the fibrotic skin phenotype over many years, as seen in adult KS patients. 
Table 1. Mutations and main clinical features indicating fibrosis of skin and mucous membranes in KS patients investigated in this study

\begin{tabular}{|c|c|c|c|c|c|c|}
\hline Patient & $\begin{array}{l}\text { Age }(y), \\
\text { Gender }\end{array}$ & $\begin{array}{l}\text { Mutations } \\
\text { DNA }^{1}\end{array}$ & $\begin{array}{l}\text { Mutations } \\
\text { Protein }\end{array}$ & Fibrosis in skin & Fibrosis in mucous membranes & Reference \\
\hline 1. & $7, \mathrm{~F}$ & c.676dup & p.Gln226ProfsX17 & Not present & Not present & Kern et al., 2007 \\
\hline 2. & $28, \mathrm{~F}$ & g.80929_89169del ${ }^{2}$ & C-terminal truncation & Webbing and contractures of the fingers & $\begin{array}{l}\text { Congenital vaginal and anal atresia, fusion } \\
\text { of labia majora and minora }\end{array}$ & Has et al., $2008 \mathrm{~b}$ \\
\hline 3. & $32, \mathrm{M}$ & g.80929_89169del & C-terminal truncation & $\begin{array}{l}\text { Webbing and contractures of the fingers, } \\
\text { pseudoainhum }\end{array}$ & Ectropion, urethral stenosis & Has et al., $2008 \mathrm{~b}$ \\
\hline 4. & $7, \mathrm{~F}$ & $\begin{array}{l}\text { g. } 70250 \_74168^{2} / \\
\text { c.910G }>\mathrm{T}\end{array}$ & $\begin{array}{l}\text { p.[Pro381Argfs }+ \\
\text { Glu304X] }\end{array}$ & Not present & Not present & Has et al., 2006 \\
\hline 5. & $10, \mathrm{M}$ & c. $328 \mathrm{C}>\mathrm{T}$ & p.Arg110X & Not present & Not present & Has et al., 2009 \\
\hline 6. & $20, \mathrm{~F}$ & c.676dup & p.Gln226ProfsX17 & $\begin{array}{l}\text { Webbing and contractures of the fingers, } \\
\text { pseudoainhum }\end{array}$ & $\begin{array}{l}\text { Microstomy, esophageal stenosis, fusion } \\
\text { of labia majora and minora }\end{array}$ & Mansur et al., 2007 \\
\hline 7. & $25, \mathrm{~F}$ & g.70250_74168del & p.Pro381Argfs & Webbing of fingers & $\begin{array}{l}\text { Microstomy, esophageal stenosis, } \\
\text { ectropion }\end{array}$ & Has et al., 2006 \\
\hline 8. & $27, \mathrm{M}$ & c. $1718+1 \mathrm{G}>\mathrm{A}$ & C-terminal truncation & $\begin{array}{l}\text { Webbing and contractures of the fingers, } \\
\text { pseudoainhum }\end{array}$ & $\begin{array}{l}\text { Esophageal strictures, urethral meatal } \\
\text { stenosis }\end{array}$ & Has et al., 2008 \\
\hline 9. & $28, \mathrm{M}$ & c.456dup & p.Asp153ArgfsX4 & Webbing and contractures of the fingers & Urethral meatal stenosis, anal strictures & Has et al., 2009 \\
\hline
\end{tabular}

Legend: y, years; F, female; M, male; ${ }^{1}$ if one mutation is mentioned, it is in a homozygous state; if two mutations are mentioned, the constellation is compound heterozygous; ${ }^{2}$ with respect to GenBank AL118505.17. The GenBank reference sequence was NM 017671.4. Nucleotide numbering reflects cDNA numbering with +1 corresponding to the A of the ATG translation initiation codon in the reference sequence according to the HGVS guidelines. 
Supplemetary Table 1. Primers used in this study

\begin{tabular}{|c|c|c|c|}
\hline Gene & Orientation & Sequence 5'-3' & $\begin{array}{l}\text { Annealing } \\
\text { temperature }\end{array}$ \\
\hline \multirow[t]{2}{*}{$I L-20$} & $\mathrm{~F}$ & tttgcaagacacaaagcctg & 51 \\
\hline & $\mathrm{R}$ & tggtaagaaaggaattggcg & \\
\hline \multirow[t]{2}{*}{$I L-24$} & $\mathrm{~F}$ & tgtggactttagccagaccc & 52 \\
\hline & $\mathrm{R}$ & aaagtggaattcttggccet & \\
\hline \multirow[t]{2}{*}{ ILIF5 } & $\mathrm{F}$ & gcagactccacagctcccgc & 60 \\
\hline & $\mathrm{R}$ & cttcattcggaagcacagcgcc & \\
\hline \multirow{2}{*}{ TGFB2 } & $\mathrm{F}$ & cctccgaaaatgccatcccgec & 60 \\
\hline & $\mathrm{R}$ & gcactctggcttttgggttctgc & \\
\hline \multirow[t]{2}{*}{$T G F B 1$} & $\mathrm{~F}$ & gggactatccacctgcaaga & 60 \\
\hline & $\mathrm{R}$ & ctccttggcgtagtagtcgg & \\
\hline \multirow[t]{2}{*}{$T N F a$} & $\mathrm{~F}$ & ccccagggacctctctctaat & 60 \\
\hline & $\mathrm{R}$ & agggtttgctacaacatggg & \\
\hline \multirow[t]{2}{*}{$C T G F$} & $\mathrm{~F}$ & taccaatgacaacgectcct & 60 \\
\hline & $\mathrm{R}$ & tgcactttttgcccttctta & \\
\hline \multirow[t]{2}{*}{$P D G F B$} & $\mathrm{~F}$ & ctctgctgctacctgcgtct & 60 \\
\hline & $\mathrm{R}$ & atcttcctctccggggtct & \\
\hline \multirow[t]{2}{*}{ COLIA1 } & $\mathrm{F}$ & agagcatgaccgatggattc & 51 \\
\hline & $\mathrm{R}$ & ccttcttgaggttgecagtc & \\
\hline \multirow[t]{2}{*}{ FERMT1 } & $\mathrm{F}$ & cattactgatatccctaaacttgc & 50 \\
\hline & $\mathrm{R}$ & ttggatttgtgtctttttgc & \\
\hline \multirow[t]{2}{*}{ FERMT2 } & $\mathrm{F}$ & gaagttgatgaagttgatgctgccctttc & 60 \\
\hline & $\mathrm{R}$ & agactgattcggatggatgc & \\
\hline \multirow[t]{2}{*}{ ITGAI } & $\mathrm{F}$ & tgaccatgaattttgagcca & 60 \\
\hline & $\mathrm{R}$ & catcaagaacaggcccattt & \\
\hline \multirow[t]{2}{*}{ ITGA2 } & $\mathrm{F}$ & gtgaggacggactttgcatt & 60 \\
\hline & $\mathrm{R}$ & cttggaaactgagagacgcc & \\
\hline \multirow[t]{2}{*}{ ITGBI } & $\mathrm{F}$ & tacttgtgaagccagcaacg & 60 \\
\hline & $\mathrm{R}$ & ggggtaatttgtcccgactt & \\
\hline \multirow[t]{2}{*}{ KRT5 } & $\mathrm{F}$ & caacccactagtgcctggtt & 51 \\
\hline & $\mathrm{R}$ & ccacttggtgtccagaacct & 51 \\
\hline \multirow[t]{2}{*}{$18 S$} & $\mathrm{~F}$ & tcaagaacgaaagtcggagg & 52 \\
\hline & $\mathrm{R}$ & gtgaggtttcccgtgttgag & \\
\hline \multirow[t]{2}{*}{ HPRT1 } & $\mathrm{F}$ & aagatggtcaaggtcgcaag & 52 \\
\hline & $\mathrm{R}$ & aagcagatggccacagaact & 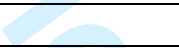 \\
\hline \multirow[t]{2}{*}{$G A P D H$} & $\mathrm{~F}$ & BD Biosciences Clontech & 60 \\
\hline & $\mathrm{R}$ & BD Biosciences Clontech & $+2 x^{2}$ \\
\hline
\end{tabular}

Legend : $\mathrm{F}$, forward ; $\mathrm{R}$, reverse 
Supplementary Table 2. Antibodies used in this study

\begin{tabular}{|c|c|c|c|}
\hline \multicolumn{4}{|l|}{ Commercially available primary antibodies } \\
\hline Antigen protein & $\begin{array}{l}\text { Clone / } \\
\text { Reference }\end{array}$ & Company & Application \\
\hline Anti human IL-10 & AF217NA & R\&D Systems & IB \\
\hline Anti human IL-20 & AF1102 & R\&D Systems & IB \\
\hline Anti human IL-24 & AF1965 & R\&D Systems & IB \\
\hline Anti human IL-24 (biotinylated) & BAF1965 & R\&D Systems & ELISA \\
\hline CD 68 & PG-M1 & Dako & $\mathrm{IB}, \mathrm{IF}$ \\
\hline Collagen I & R1038X & Acris & IB \\
\hline Collagen VII & MAB2501 & Chemicon & IF \\
\hline Collagen VII & LH7.2 & Calbiochem & IF \\
\hline CTGF & 88430 & R\&D Systems & IF \\
\hline 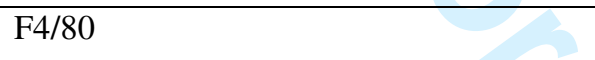 & BM8 & Abcam & IF \\
\hline Fibronectin & ab2413 & Abcam & IB \\
\hline GAPDH & $6 \mathrm{C} 5$ & Millipore & IB \\
\hline IL-6 & SC-130326 & Santa Cruz, Inc & IF \\
\hline phospho STAT 3 (Tyr 705) & D3A7 & Cell Signaling & IB,IF \\
\hline STAT3 & $124 \mathrm{H} 6$ & Cell Signaling & $\mathrm{IB}, \mathrm{IF}$ \\
\hline Tenascin C & 578 & R\&D Systems & IF, IB \\
\hline TGF- $\beta 1$ & G122A & Promega & IF \\
\hline TRITC-conjugated Phalloidin & & Chemicon & IF \\
\hline$\alpha$-smooth muscle actin - Cy3 & $1 \mathrm{~A} 4$ & Sigma & IB, IF \\
\hline TNF alpha & ab6671 & Abcam & $\mathrm{IB}, \mathrm{IF}$ \\
\hline$\beta$ tubulin & ab15568 & Abcam & IB, IF \\
\hline Secondary antibodies & & 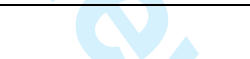 & \\
\hline $\begin{array}{l}\text { anti-rabbit IgG, horseradish peroxidase } \\
\text { labeled }\end{array}$ & $172-1019$ & Bio-Rad & IB \\
\hline $\begin{array}{l}\text { anti-mouse } \mathrm{IgG}, \text { horseradish peroxidase } \\
\text { labeled }\end{array}$ & $172-1011$ & Bio-Rad & IB \\
\hline Alexa 488 goat anti-rabbit IgG & A11006 & Invitrogen & IF \\
\hline Alexa 488 goat anti-mouse IgG & A11011 & Invitrogen & IF \\
\hline Alexa 594 goat anti-mouse IgG & A11020 & Invitrogen & IF \\
\hline Alexa 488 chicken anti-mouse IgG & A21200 & Invitrogen & IF \\
\hline Alexa 647 donkey anti-goat IgG & A21442 & Invitrogen & IF \\
\hline
\end{tabular}

Legend: IB, immunoblotting; IF, immunofluorescence 